\title{
Plate boundary deformation between the Pacific and North America in the Explorer region
}

\author{
Corné Kreemer ${ }^{\mathrm{a}, *}$, Rob Govers ${ }^{\mathrm{a}}$, Kevin P. Furlong ${ }^{\mathrm{b}}$, William E. Holt ${ }^{\mathrm{c}}$ \\ ${ }^{a}$ Department of Earth Sciences, Utrecht University, Utrecht, Netherlands \\ ${ }^{b}$ Department of Geosciences, Pennsylvania State University, University Park, PA 16802, USA \\ ${ }^{c}$ Department of Geosciences, SUNY at Stony Brook, Stony Brook, NY 11794-2100, USA
}

Received 23 April 1997; accepted 3 April 1998

\begin{abstract}
One of the consequences of plate tectonics is that a spreading ridge will eventually approach a subduction zone. The problem whether the possible break-up of the approaching ridge will lead to the development of independent micro-plates, or not, is still unresolved. Some 4 million years ago the interaction between the Juan de Fuca Ridge and the Cascadia subduction zone resulted in ridge fragmentation in the Explorer region. There are two proposed post-Miocene kinematic models: one that proposes the presence of a micro-plate and the other that treats the region as a transform deformation zone, or so-called pseudo-plate. We use earthquake strain rates derived from 74 events since 1948 to estimate a long-term velocity field for the region. By comparing this result with the predicted velocity fields for both models we try to discriminate between the two. The earthquake strain rates indicate the presence of a transform deformation zone between the North American (NAM) and Pacific (PAC) plates. The velocity field derived from the inversion of the earthquake strain rates indicates that seismic activity takes up $50 \pm 30 \%(1 \sigma)$ of the PAC-NAM relative motion (NUVEL-1A; DeMets et al., 1994. Effect of recent revisions to the geomagnetic reversal time scale on estimates of current plate motions. Geophys. Res. Lett. 21, 2191-2194.) within the seismogenic layer of this zone and is indistinguishable in direction from the NUVEL-1A PAC-NAM model. The presence of this Explorer transform zone is consistent with the strain rate and velocity field for the 'pseudo-plate model' and indicates that seismicity defines a (new) plate boundary zone between the Pacific and North American plates. Earthquake-derived strain rates are low along the Nootka Transform, which accommodates relative motion between the Juan de Fuca and North American plates. The cause for the absence of significant seismic slip along this transform is unclear and may be closely linked to the fact that the adjacent Cascadia subduction zone is locked. The 'micro-plate model', which we reject, predicts SW-NE convergence in the eastern Explorer region and this is inconsistent with the earthquake strain rates as well as with surface fault observations. (C) 1998 Elsevier Science B.V. All rights reserved.
\end{abstract}

Keywords: geodynamics; plate boundaries; Pacific plate; deformation; lithosphere; triple junctions

\footnotetext{
* Corresponding author. Present address: Department of Geosciences, SUNY at Stony Brook, Stony Brook, NY 11794-2100, USA.

Fax: +1 (516) 632-8240; E-mail: kreemer@ seism1.ess.sunysb.edu
} 


\section{Introduction}

The approach of an oceanic spreading ridge to a subduction zone is one of the consequences of plate tectonics. This may lead to fragmentation of the oceanic plate, e.g. like the break-up of the former Farallon plate into smaller entities (Atwater, 1989; Lonsdale, 1991). As to the nature of these fragments, i.e. whether these fragments are individual microplates or not, questions still remain. The Explorer region, offshore Vancouver Island in the northeast Pacific, provides an excellent opportunity to resolve these issues. Here, the interaction of the Juan de Fuca Ridge and the Cascadia subduction zone has recently led to the fragmentation of the Juan de Fuca plate in a series of rift-propagation events (Botros and Johnson, 1988).

The Juan de Fuca (JdF), Pacific (PAC) and North American (NAM) plates intersect in the Explorer (triple junction) region (Fig. 1). Spreading between the JdF and PAC plates takes place at the Juan de Fuca Ridge. Convergence between the NAM and JdF plates occurs along the Cascadia subduction zone. The transform boundary between the PAC and NAM plates is defined by the Queen Charlotte Fault (QCF). The Nootka Transform has been proposed as the northern boundary of the JdF plate (Riddihough and Hyndman, 1989), but its nature and exact location are questionable.

Two different models have been proposed for the post-Miocene kinematics of this region. In the classic tectonic model the Explorer region is assumed to be an independent rigid entity (plate) that is moving towards the NAM plate, with a possible component of subduction (Riddihough and Hyndman, 1989) (Fig. 1A). This model places triple junctions at both ends of the Nootka Transform and another on the continental margin at the southern end of the QCF. We will refer to this model as the 'micro-plate model'. In the alternative kinematic model the area designated as the Explorer plate is a pseudo-plate (Rohr and Furlong, 1995; Govers et al., 1998). This implies that the Explorer plate region is a transform deformation zone between the NAM and PAC, in-
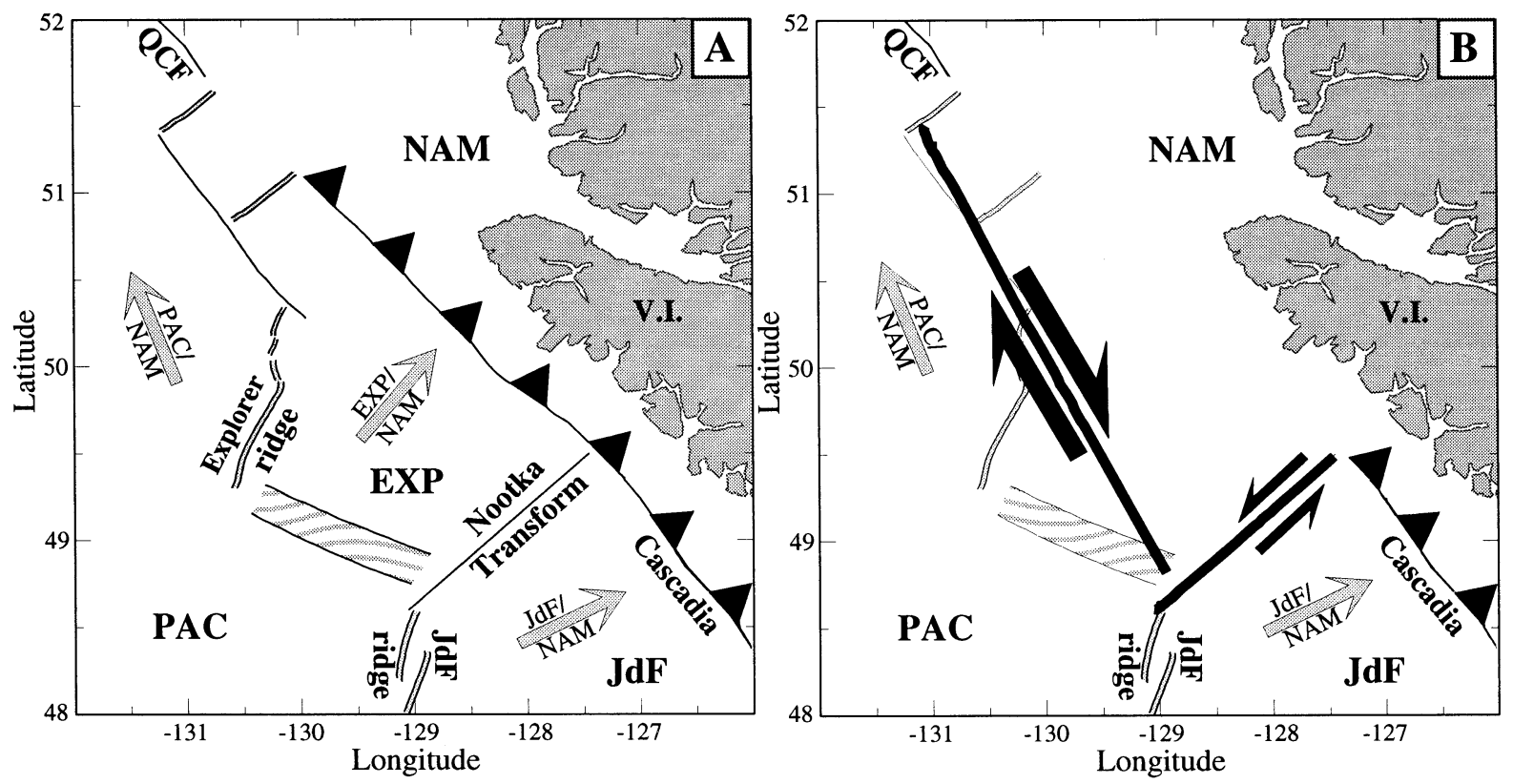

Fig. 1. (A) Major tectonic features describing the micro-plate model for the Explorer region. The Explorer plate $(E X P)$ is an independent plate and is in convergent motion towards the North American plate $(N A M)$. V.I. $=$ Vancouver Island; PAC $=$ the Pacific plate; $J d F=$ the Juan the Fuca plate. The accentuated zone between the Explorer and JdF ridges is the Sovanco transform zone and the two boundary lines do not indicate the presence of faults but define the boundaries of this zone of complex deformation. (B) The key features of the pseudo-plate model for the region are a major plate boundary transform fault zone between the North American and Pacific plates and the Nootka Transform, a left-lateral transform fault north of the Juan the Fuca plate. 
stead of an independent plate (Fig. 1B). This model requires only one triple junction in the region at the left edge of the Nootka Transform. This model is referred to as the 'pseudo-plate model'.

The two alternative models predict distinct kinematic patterns. The aim of this study is to try to discriminate between these two alternatives by determining the strain rate field associated with the focal mechanisms of well-studied earthquakes to derive a velocity field for the region. This enables us to quantitatively compare the inversion results with velocity fields that are predicted by the two alternative models. Discrimination between the two models is important for a better understanding of the processes related to the approach of oceanic spreading centers to subduction zones, and may serve as an analog for the past kinematic evolution of micro-plates offshore southern California.

\section{Theory}

Our goal is to calculate the motion across the plate boundary zone in order to discriminate between kinematic models. We calculate a continuous seismic strain rate field and solve for a vertically averaged velocity field within the seismogenic layer. Although these calculations only account for the seismogenic layer, rigid plate constraints require that integrated strain rates across the plate boundary in the lower, aseismic, portion of the lithosphere yield a motion in accord with the integrated total motion across the plate boundary zone in the top portion of the lithosphere. Therefore, even though our measurements and results pertain to motions associated with the seismic deformation, the constraints provided by plate tectonics allows us to make inferences about the accommodation of the motion of the lithosphere as a whole (Bourne et al., 1988).

At large horizontal length scales, by which we mean at dimensions several times the seismogenic thickness, it is appropriate to approximate horizontal deformation to be continuous, which can then be described by a continuous velocity field (e.g. England and McKenzie, 1982; McKenzie and Jackson, 1983). Consequently, this makes a detailed study of the small-scale deformation within the seismogenic layer by discontinuous faulting impossible. More- over, the modelling of the deformation field as a number of individual dislocations involves the implicit assumption that where there is no measured seismicity, the deformation field is expected to be zero. The continuum approach adopted in this study makes no such assumption and is therefore more appropriate for investigating the characteristics of the long-term seismic strain rate field, which we are seeking.

Although earthquakes can provide information about the strain tensor, this by itself is not enough to define the total kinematics (relative velocities and rotations) in a region (McKenzie and Jackson, 1983; Jackson and McKenzie, 1988). The reason for this is that the summation of seismic moment tensors will only produce the symmetric strain rate tensor and not the anti-symmetric tensor related to rigid body rotations. This limitation may be overcome when the strain rate field is known everywhere, such that the complete velocity gradient tensor within the deforming zone can be recovered (Haines, 1982).

A measure of the strain rate tensor can be obtained by an earthquake moment tensor summation over a certain cell area (Kostrov, 1974):

$\dot{\varepsilon}_{i j}=\frac{1}{2 \mu V T} \sum M_{0} m_{i j}$

where $\mu$ is the shear modulus, $V$ is the cell volume (the cell area times the seismogenic thickness), $T$ is the time period of the earthquake record, $M_{0}$ the seismic moment and $m_{i j}$ the unit moment tensor. Here, cell dimensions need to be specified in a way that guarantees that the style of deformation within a cell is approximately uniform. Uncertainties in the strain rate tensor values in Eq. 1 are defined by assigning a conservative standard error of $\pm M_{0} m_{i j}$ for each event plus an incompleteness factor for each area (Haines et al., 1998). The treatment of errors accounts for the randomness of earthquakes in space and time as well as for the possible incompleteness of the earthquake catalogue (Shen-Tu et al., 1998). The latter is caused by the fact that recurrence times of earthquakes on individual faults are typically much longer than the time interval for which quantifiable seismological data are available. The contribution in the total error associated with focal mechanism uncertainties is small in comparison with our conservative error estimate of $\pm M_{0} m_{i j}$ for each 
moment tensor to account for the random process of earthquake occurrence (Shen-Tu et al., 1998) and so it is ignored here.

Bi-cubic spline functions have been used to determine a continuous strain rate field for various regions (e.g. Holt and Haines, 1995; Tinnon et al., 1995; Shen-Tu et al., 1995) and this method is a variant of the method that used polynomials (Haines and Holt, 1993). The main advantage of using spline functions to model continuous strain rate fields, rather than polynomials, is that splines can be constrained to simulate a rigid plate. This allows us to apply rigid plate constraints (e.g. NUVEL-1A model; DeMets et al., 1994) in our inversions.

The horizontal strain rate field is inverted to obtain the rotation vector function $\overline{\mathbf{W}}(\hat{x})$ that describes a continuous horizontal velocity field $\overline{\mathbf{u}}(\hat{x})$ on a sphere:

$\overline{\mathbf{u}}(\hat{x})=r[\overline{\mathbf{W}}(\hat{x}) \times \hat{x}]$

where $r$ is the earth's radius and $\hat{x}$ the unit radial vector. The set of equations that relate the rotation vector $\overline{\mathbf{W}}(\hat{x})$ to the horizontal strain rates on the surface of a sphere are (Haines and Holt, 1993):

$\dot{\varepsilon}_{\phi \phi}=\frac{\hat{\Theta}}{\cos \theta} \cdot \frac{\partial \overline{\mathbf{W}}}{\partial \phi}$

$\dot{\varepsilon}_{\theta \theta}=-\hat{\Phi} \cdot \frac{\partial \overline{\mathbf{W}}}{\partial \theta}$

$\dot{\varepsilon}_{\theta \phi}=\frac{1}{2}\left(\hat{\Theta} \cdot \frac{\partial \overline{\mathbf{W}}}{\partial \theta}-\frac{\hat{\Phi}}{\cos \theta} \cdot \frac{\partial \overline{\mathbf{W}}}{\partial \phi}\right)$

Values of $\overline{\mathbf{W}}(\hat{x})$ are derived at all nodal points on the grid such that the predicted values of strain rates within the grid areas match the observed values of strain rate in a least-square sense. The values for $\overline{\mathbf{W}}(\hat{x})$ between the nodal points are determined by spline interpolation.

'Smoothing' is incorporated in the procedure in three consecutive steps: (1) the seismic moment tensor summation will give an average of the strain rate in each single grid area, which is dependent on the cell size; (2) spatially smoothing of the data and their variances and covariances has to be done to avoid problems associated with trying to estimate longterm average strain rates and velocity fields from data of short duration (Haines et al., 1998); and (3) possible smoothing related to mapping of the data onto bi-cubic splines. The smoothing associated with the fitting of spatial averages of strain rates is rarely a problem as the splines are generally able to accommodate rapid spatial variations in strain rate. Later we address in detail the effects of data smoothing on our kinematic results.

\section{Earthquake data}

Our catalogue of regional seismicity comprises 74 events with known focal mechanisms that occurred between 1948 and August 1996 (Cassidy et al., 1988; Zoback et al., 1989; Wahlström et al., 1990; Cassidy and Rogers, 1995; the Oregon State University (OSU) moment tensor catalog; the Harvard CMT catalog — see Dziewonski et al., 1994, and references therein). The total seismicity in this region is shown in Fig. 2A and focal mechanisms of major events in Fig. 2B. Magnitudes of all events range between 4.0 and 7.0. For events prior to the CMT catalogue, $M_{0}$ was determined from either $M_{\mathrm{s}}$ or $m_{\mathrm{b}}$ using the relationships in Nuttli (1985).

Magnitude-frequency analysis (Ward, 1994) was done for magnitudes between 5.2 and 6.8. Using a simple two-parameter truncated Gutenberg-Richter law, a complete catalogue with a maximum amplitude of 7.2 predicts a total moment rate of $2.23 \times 10^{18}$ $\mathrm{N} \mathrm{m} / \mathrm{yr}$, while our catalogue contains a total moment rate of $2.28 \times 10^{18} \mathrm{~N} \mathrm{~m} / \mathrm{yr}$, suggesting that the catalogue is reasonably complete within the region considered.

\section{Inversion results}

\subsection{Strain rates and velocity field associated with earthquake strain rates}

The strain rates derived from Kostrov's summation of the focal mechanisms in our earthquake catalogue (hereafter called the observed strain rates) are shown in Fig. 3A together with the predicted strain rates. Before the inversion of the data values, the variances and covariances were smoothed. The predicted average strain rates are obtained from the 

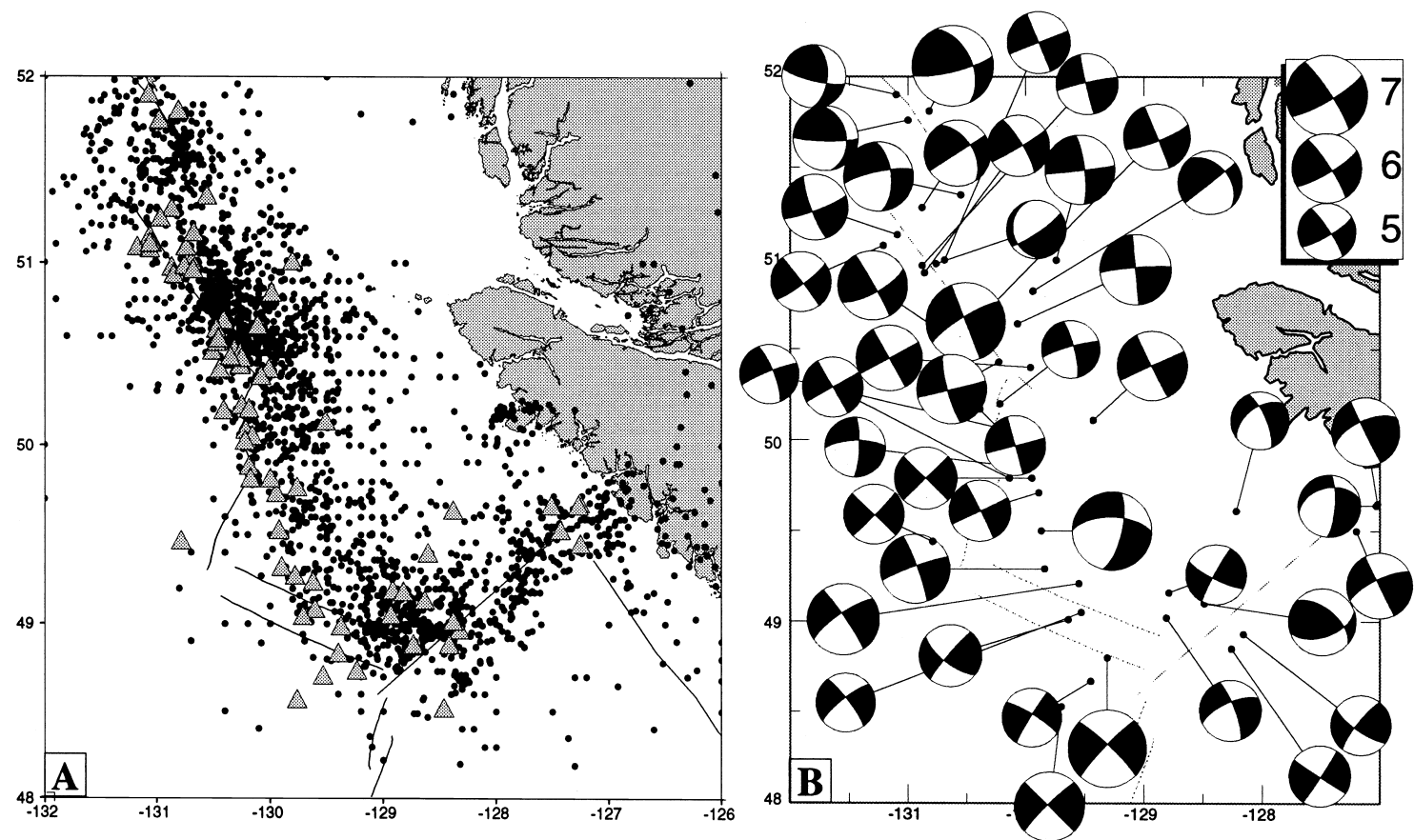

Fig. 2. (A) Map with total seismicity for $M>2.0$ between 1793 and 1990 (black spots), taken from the Canadian Earthquake Epicentre File provided by the Geological Survey of Canada. Grey triangles are locations of the well-studied events for which focal mechanisms were available. (B) Epicenters and focal mechanisms of the larger events $\left(M_{\mathrm{w}}>5.0\right)$ between 1948 and 1996 as used in our inversion (Cassidy et al., 1988; Zoback et al., 1989; Wahlström et al., 1990; Cassidy and Rogers, 1995; the Oregon State University (OSU) moment tensor catalog; the Harvard CMT catalog — see Dziewonski et al., 1994, and references therein).

bi-cubic spline functions fitted to the data. As input parameters a shear modulus of $30 \mathrm{GPa}$ and a seismogenic thickness of $6 \mathrm{~km}$ (appropriate for the young lithosphere of the region) were used. Strain rates show the localization of strike-slip deformation in a zone that cuts the Explorer region, but there is little deformation near the Nootka Transform. The width of the deformation zone is consistent with observations of vertical faults that cut the surface (Fig. 4) (Furlong et al., 1994). Seismic reflection profiles show that these faults are dominantly strike-slip and have a bearing between $340^{\circ}$ and $050^{\circ}$ (Rohr and Furlong, 1997).

The velocity field from the inversion of the predicted strain rates is shown in Fig. 3B. The error ellipses represent $1 \sigma$ standard deviation, which, because of the conservative error analysis that we take, are not proportional to the total misfit of any region, but rather reflect the uncertainty in the earthquake strain rates implied by the randomness of earthquake occurrence and the possible incomplete- ness of the seismic moment release. Deformation across the zone yields a relative motion that is about $50 \pm 30 \%(1 \sigma)$ of the PAC/NAM relative motion of $46.9 \mathrm{~mm} / \mathrm{yr}$ (DeMets et al., 1994). The direction of relative motion is consistent with the PAC/NAM relative motion from the NUVEL-1A model (DeMets et al., 1994). The region east of the Explorer ridge is moving with a velocity of $\sim 0.25 \mathrm{~mm} / \mathrm{yr}$ with respect to NAM. Since seismicity reveals little significant deformation along the Nootka Transform, the velocity field lacks any consistency with the JdF/NAM relative plate motion of $45.7 \mathrm{~mm} / \mathrm{yr}$ (Wilson, 1993), which is inferred from analysis of magnetic anomalies within the JdF plate.

Very recently epicenters of earthquakes since 1994 in the region were relocated (Braunmiller et al., 1996), resulting in a significant average shift by $25 \mathrm{~km}$ to the west-southwest. We recalculated the velocity field with these new epicenter locations. This resulted in local differences in the velocity magnitude of less than $4 \%$ from the earlier result. 


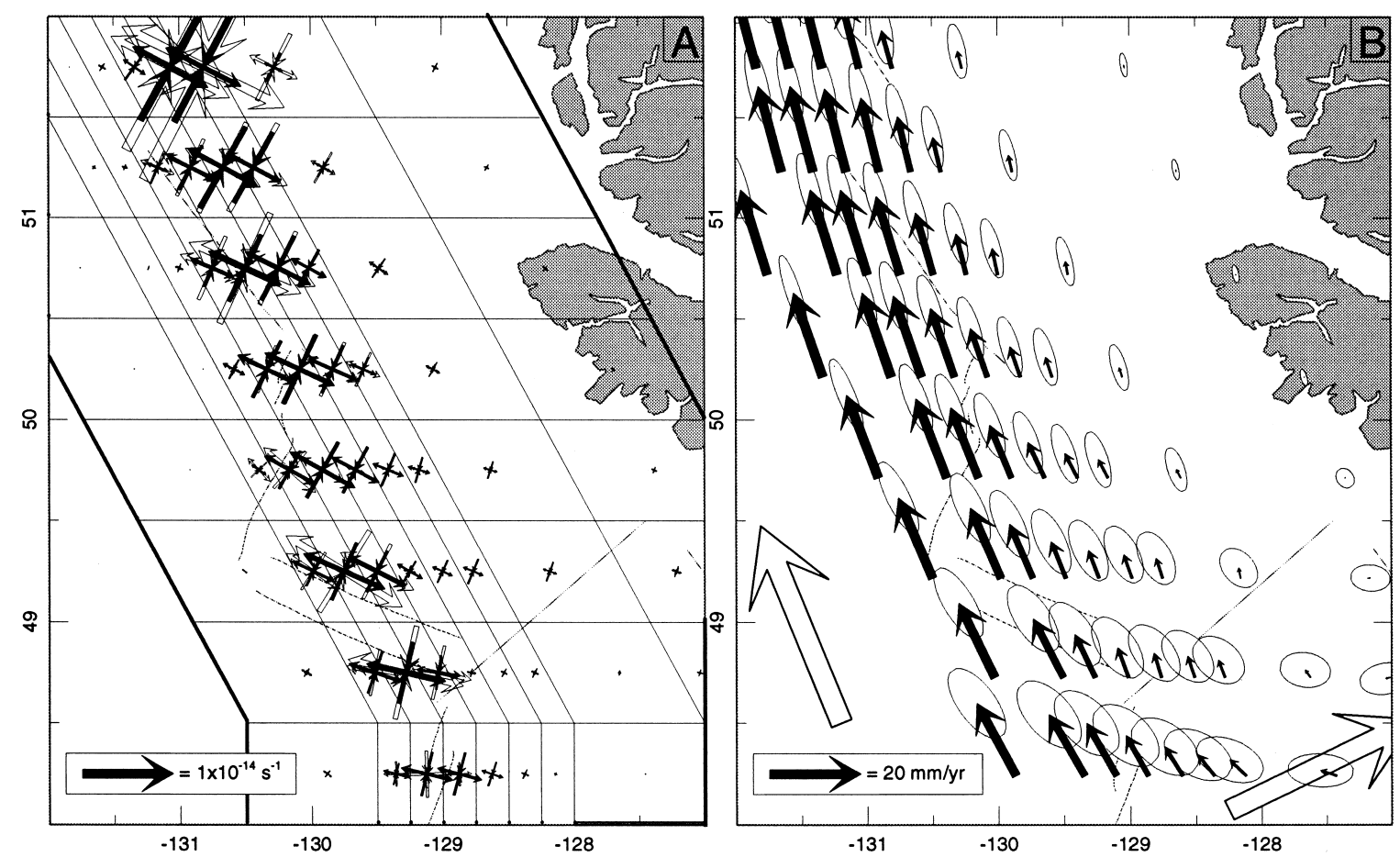

Fig. 3. (A) Observed strain rates (white principal strain axes) from earthquake data and predicted average strain rates for each cell area (black principal axes) plotted on contours of main tectonic features, together with the grid geometry (thick solid lines are boundaries with the rigid PAC, NAM and JdF plates). Observed strain rates are smoothed over a single grid radius and the associated variances and covariances over 4 grid areas (see text, Section 4.2.3). (B) Velocity field from inversion relative to NAM. White arrows indicate present-day plate motions of the JdF plate relative to NAM (Wilson, 1993) and PAC plate relative to NAM (DeMets et al., 1994). Error ellipses are for $1 \sigma$ formal standard error.

The direction of local velocities and the direction and magnitude of the total motion accommodated across the zone, however, was unchanged. The small differences in local magnitudes of velocity are a consequence of the fact that all the events since 1994 had a magnitude less than 5.4, where it appears that only earthquakes with magnitudes higher than 6.0 have a significant contribution to the strain rate field. The focal mechanisms for the larger events are wellstudied and an accurate epicenter location can be assumed

\subsection{Sensitivity to inversion parameters}

The velocity field estimate obtained from seismic strain rates is not a unique solution since it is sensitive to a variety of parameters including assumed seismogenic thickness and shear modulus, grid geometry, and the extent of data smoothing.
To determine how robust our result is, we test the sensitivity to variations in these variables.

\subsubsection{Shear modulus and seismogenic thickness}

The calculation of deformation rates from the seismic moment tensor is, by means of Kostrov's formula, related to the seismogenic thickness in the region considered and the shear modulus for this seismogenic layer. For an extremely young oceanic lithosphere, as is present in the Explorer region, these parameters are poorly known. The $600^{\circ} \mathrm{C}$ isotherm could be considered as the lower boundary for the seismogenic layer (Wiens and Stein, 1983). Using the relationship for the half-space cooling model with $\kappa=32 \mathrm{~km}^{2} / \mathrm{Ma}$ and a mantle temperature of $1300^{\circ} \mathrm{C}$, the depth of this $600^{\circ} \mathrm{C}$ isotherm for a $1-2$ Ma old oceanic lithosphere is between 6 and $7 \mathrm{~km}$. (However, it should be stated that the use of this cooling model is arguable for such extremely young 


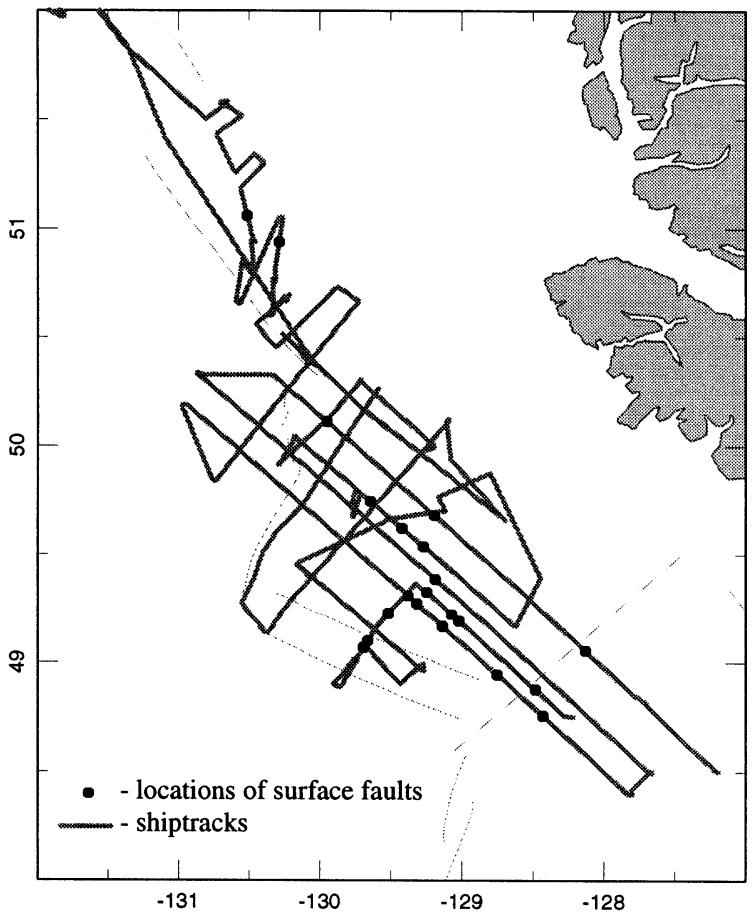

Fig. 4. Observed locations of faults cutting the sea floor (Furlong et al., 1994; Rohr and Furlong, 1997). Faults have a bearing from $340^{\circ}$ to $050^{\circ}$ and show dominantly strike-slip motion.

lithosphere.) This depth agrees with the maximum $6 \mathrm{~km}$ depth for the occurrence of seismicity, which was determined with ocean bottom seismographs (OBS) in this region (Hyndham and Rogers, 1981). We also tried depths of 3 and $8 \mathrm{~km}$, which are the more general minimum and maximum depths for the seismogenic layer of the oceanic crust. Obviously, different seismogenic thicknesses will change the estimate for magnitude of strain rates and velocity; i.e. magnitudes will double when using a thickness of $3 \mathrm{~km}$.

The other important parameter is the shear modulus. Its value for a young hot lithosphere is not well known, but will probably range between 20 and 30 GPa based on the properties of young basalt (Hatheway and Kiersch, 1982). Consequently, taking a seismogenic thickness of $6 \mathrm{~km}$, the percentage of the NUVEL-1A PAC/NAM relative motion accommodated by seismic release in the Explorer transform zone varies from 42 to $63 \pm 30 \%(1 \sigma)$. Although shear modulus and seismogenic thickness can have significant influence on the magnitude of deformation, they do not affect the style of deformation.

\subsubsection{Model geometry and spatial discretization}

We defined an irregular grid with a dense spacing along the observed band of seismicity through the Explorer region (Fig. 3). The small grid spacing in this area of seismicity will allow a more refined spatial resolution of the strain, whereas an equal spaced grid (Fig. 5A) would tend to distribute the strain more evenly. This form of strain data smoothing will not have a significant effect on the direction of the velocity field (Fig. 5B), but will influence velocity magnitudes locally between the PAC and NAM plates, as is shown by the residuals in Fig. 5C. However, since the total integral of strain release over the zone between the PAC and NAM plates should be preserved, the velocity at the PAC plate boundary is consistent in magnitude and direction with the velocity that was estimated with the original geometry (Fig. 3A). Residuals from the inversion with the use of the grid in Fig. 5D show that further decrease of the grid area size will change the result very little (Fig. 5F). A further decrease of grid area sizes will lead to a geologically unrealistic spatial variation of observed strain rates; cells with high strain rates will be adjacent to some whose low strain rates reflect only the lack of earthquakes in our 48-year catalogue, not the lack of active seismic deformation over the long term.

Because the objective of this study is to distinguish between two alternative kinematic models that describe the plate tectonic setting in the region, the placing of the major boundaries between the Explorer region and the rigid JdF, PAC and NAM plates was done in a conservative manner. That is, we chose the grid boundaries to be far from the major seismicity such that they have no effect on the fit to the observed distribution of strain rates. These grid boundaries define the boundaries between the deforming Explorer plate and the rigid NAM, PAC and $\mathrm{JdF}$ plates.

\subsubsection{Smoothing of data and variances/covariances}

We consider long-term lithospheric deformation as continuous, implying that the kinematics are described by a continuous differentiable velocity field. However, strain rates obtained from our time-limited 

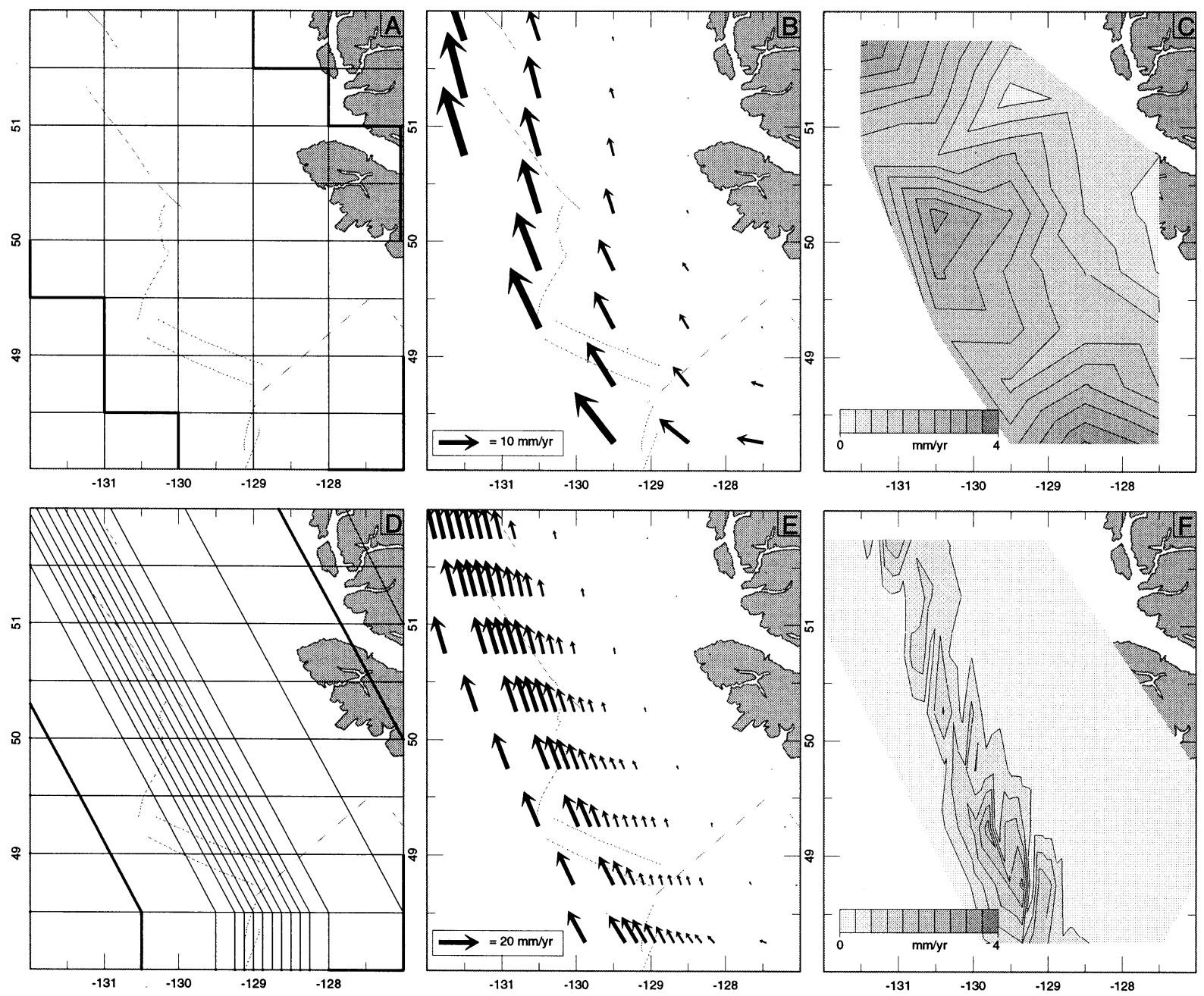

Fig. 5. (A) Rectangular grid with the thick solid lines the boundaries with the rigid plates. (B) Velocity field from the inversion using this grid. (C) Residuals between this velocity field and the result in Fig. 3B. (D) Locally more dense grid with the thick solid lines the boundaries with the rigid plates. (E) Velocity field from the inversion using this grid. (F) Residuals between this velocity field and the result in Fig. 3B.

catalogue will be incompletely sampled spatially. Thus, to go from the observed spatially discontinuous earthquake strain rates to an estimate of the long-term distribution of strain, some amount of spatial smoothing is necessary. Two different steps of smoothing are applied: smoothing of the strain rate data, and smoothing of the associated variances and covariances. The spatially discontinuous observations cannot be representative of the longterm deformation of the lithosphere. Therefore, data smoothing is necessary to reduce strain rate incompatibilities that arise when trying to fit a continuous strain rate field to spatially discontinuous observations. Smoothing of the data variances and covariances ensures that adjacent areas are likely to be straining at similar rates. Smoothing will also give a more equal weighting to the different grid areas in the least-squares inversion of the strain rate data, such that all strain rate data will be matched equally well by the resulting velocity field (Haines et al., 1998). In other words, should variances and covariances not be smoothed, this would imply that only those areas that have had earthquake activity are expected to be straining over the long term. 


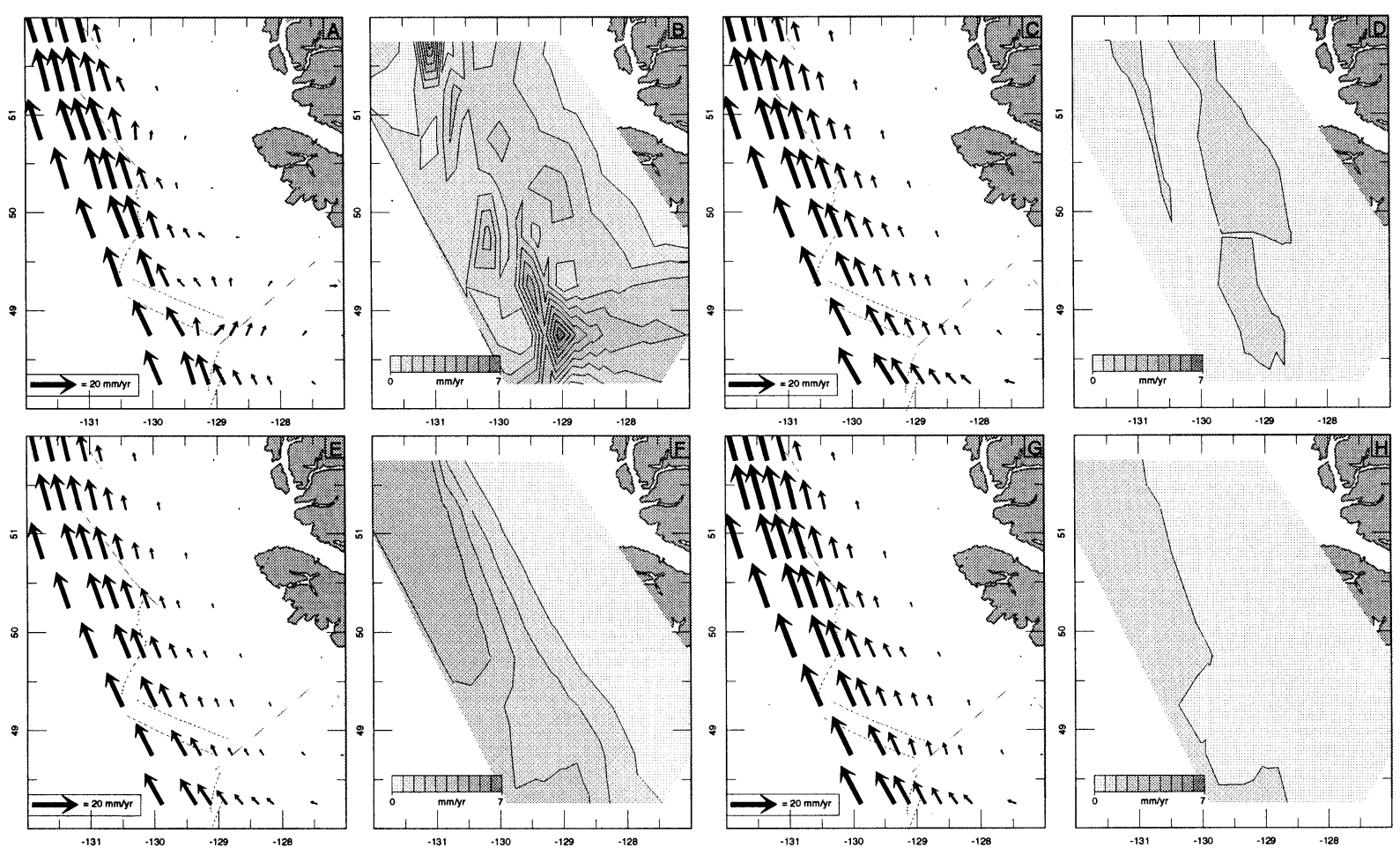

Fig. 6. (A) Velocity field from inversion with no data smoothing and 32 times smoothing of variances and covariances. (B) Residuals between this velocity field and the result in Fig. 3B, which was obtained with a single time data smoothing and 32 times smoothing of variances and covariances. (C) Velocity field from inversion with two times data smoothing and 32 times smoothing of variances and covariances. (D) Residuals between this velocity field and the result in Fig. 3B. (E) Velocity field from inversion with a single time data smoothing and 8 times smoothing of variances and covariances. (F) Residuals between this velocity field and the result in Fig. 3B. (G) Velocity field from inversion with a single time data smoothing and 72 times smoothing of variances and covariances. (H) Residuals between this velocity field and the result in Fig. 3B.

The result in Fig. 3 was obtained after smoothing the data once and the variances and covariances 32 times. The amount of smoothing steps can be expressed in terms of a kernel smoothing radius (measured in number of cells) by: radius $=\sqrt{0.5 n_{\text {smooth }}}$, with $n_{\text {smooth }}$ the number of smoothing steps. The velocity field in Fig. 6C shows that smoothing of the data more than once hardly changes the result. The same could be concluded when trying to smooth the variances and covariances more than 32 times (Fig. 6G).

\section{Forward modelling: imposing boundary velocities}

Forward modelling in this study implies the simulation of the effects of NUVEL-1A plate motions on the Explorer region. This will reveal the 'missing' deformation, because seismicity in the Explorer region only partially reflects the plate motions of the PAC and JdF plates relative to NAM; only $\sim 50 \%$ of $\mathrm{PAC} / \mathrm{NAM}$ relative motion is accommodated by the distribution of seismicity, while $\mathrm{JdF} / \mathrm{NAM}$ relative motion is not accounted for at all by seismicity along the Nootka Transform. Assuming that plate motions are the driving forces behind the deformation in the Explorer region, about half of these motions are not taken up by (catalogue based) seismic release, and may be related to aseismic deformation. To investigate the nature and contribution of this possibly missing aseismic deformation we solve for the total velocity field by minimizing the total strain within the deformation zone under the condition of plate boundary velocities (e.g. NUVEL-1A; DeMets et al., 1994) applied at the grid boundaries. In this proce- 
dure the seismic strain rates are not used to define the total velocity field. This should allow us to make a discrimination between the different velocity fields, and hence strain rate fields, that correspond to the two alternative kinematic models for the region.

There is a dynamic analogue for this forward modelling. When zero strain rate data values are used (e.g. no earthquake data), the process of minimizing the rates of strain, normalized by the variancecovariance values, is equivalent to minimizing the rate of work done by a straining viscous thin sheet in accommodating the velocity boundary conditions (Jackson et al., 1995; Holt et al., 1995; Haines et al., 1998). Consequently, the relative sizes of the data variance-covariance values assigned to the zero data values within different grid areas control the relative magnitudes of the strain rates within those areas; the higher the assigned variance-covariance value the lower the effective viscosity for that area. The presence of active faults and ridges in the Explorer region and the occurrence of seismicity only in preferred zones shows that the region cannot be considered as being homogeneous in strength. Besides, this would consequently lead to a homogeneous strain distribution and a velocity gradient over the entire zone between the PAC and NAM plates, which is inconsistent with the surface fault observations (Fig. 4). The same model geometry and grid discretization used to analyze seismic strain rates are used in the forward modelling procedure. In those areas where ridges and faults are known to be present, we assigned a viscosity that was a factor 10 lower than in surrounding areas.

\subsection{The pseudo-plate model}

Since the pseudo-plate model does not account for plate motions other than the PAC/NAM and $\mathrm{JdF} / \mathrm{NAM}$ relative motions, the only other boundary condition, next to the constraint of these plate motions on the model boundaries, is the presence of the weak zones at the locations of ridges and transform zones (Fig. 7A). The strain rate field in Fig. 7B reveals the expected total strain rate field that accommodates plate motion in the pseudo-plate model; the strain rate magnitude in the transform deformation zone is doubled from the result inferred from seismic data alone and there is major strike-slip deformation along the Nootka Transform corresponding to a left-lateral motion. Furthermore, significant extension shows up at the Juan de Fuca Ridge, which is obviously not related to any major seismicity.

Although the magnitude of the strain rates in the Explorer transform zone is doubled, the orientation of the strain rates within the zone are consistent with the orientation of the earthquake strain rates

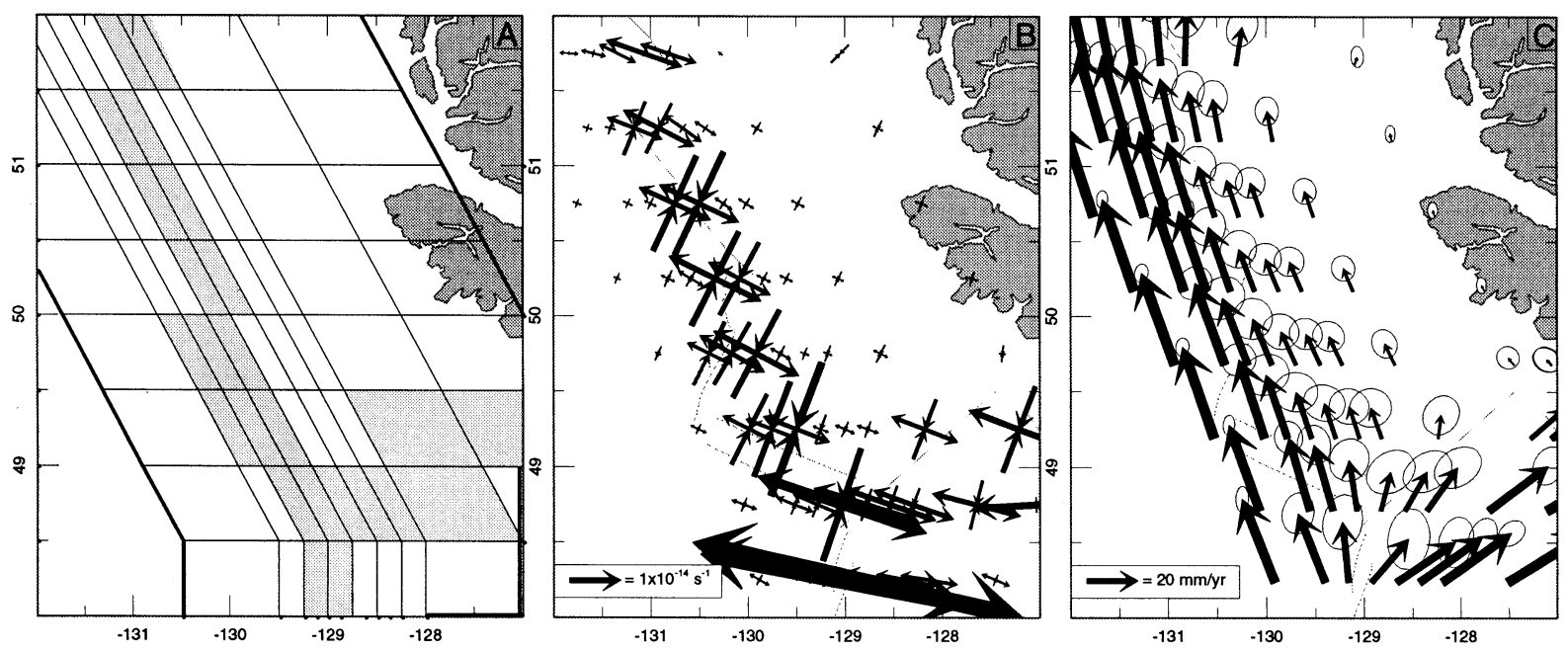

Fig. 7. (A) Grey grid areas indicate areas with a given factor of 10 higher variance than other areas, representing zones of weakness. $\mathrm{JdF} / \mathrm{NAM}$ and PAC/NAM relative plate motions are imposed on the grid boundaries (thick solid lines) with, respectively, the JdF and PAC plate. (B) Principal axes of predicted strain rates. (C) Velocity field relative to NAM. 


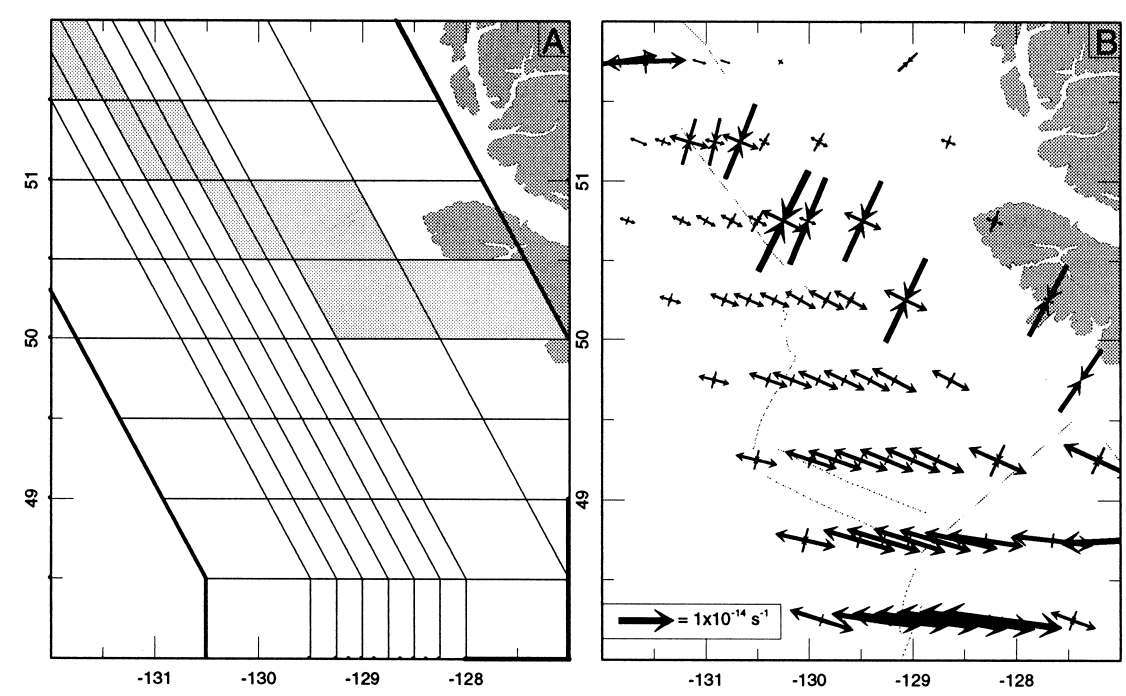

Fig. 8. (A) An alternatively, randomly chosen weaker zone indicated by the grey areas. Again, JdF/NAM and PAC/NAM relative plate motions are imposed on the grid boundaries (thick solid lines) with, respectively, the JdF and PAC plate. (B) Principal axes of predicted strain rates.

(Fig. 3A) and width of the zone is consistent with the observations of the faults cutting the sea floor (Fig. 4). In order to test how plate motions are accommodated within a zone of weakness oriented differently from that given by the earthquake observations, we designed a weak zone that cuts arbitrarily across the region (Fig. 8). The resulting strain rate field shows that the plate motions were preferably taken up in these weak zones and this is inconsistent with our result from the inverse modelling, but, most important, it is inconsistent with the surface fault observations (Fig. 4). Furthermore, the style of strain rate in this zone is incompatible with the style of focal mechanisms in this part of the region.

\subsection{The micro-plate model}

Up until now the result from seismic data as well as from the imposing of velocity boundary conditions suggest a preference for the pseudo-plate model. However, this does not indicate that the pseudo-plate model is the unique scenario for the kinematics in the Explorer region. To test the micro-plate model we used the same forward model as described above for the pseudo-plate model, but with the exception that the region east of the deforming transform zone is now constrained to more rigid behavior. We increased the relative effective viscosities by a factor of 10 , which effectively makes the area that is considered the Explorer plate in the micro-plate model, 'plate-like'. Furthermore, this plate was given a relative motion with respect to NAM (Fig. 9A). This motion was derived from the relative Explorer/PAC motion of $37 \mathrm{~mm} / \mathrm{yr}$, which was determined from magnetic anomalies along the Explorer ridge (Davis and Currie, 1993).

Deformation associated with the micro-plate model is expected to be at its boundaries, i.e. along the Explorer ridge and Nootka Transform and between the Explorer plate and northern Vancouver Island. The results of the forward modelling show the absence of high strain rates along the Nootka Transform (Fig. 9B). The weak zone west of the Explorer plate show strike-slip deformation consistent with the localization of the earthquake strain rates, but near the Explorer ridge the model strain rates have an additional component of ESE-WNW extension added to the strike-slip deformation. This can easily be explained by a component of aseismic extension, which may be expected along a young hot oceanic ridge. However, since $50 \pm 30 \%(1 \sigma)$ of PAC/NAM relative motion is taken up seismically, some seismic strains would have been expected in this region related to Explorer/NAM relative motion, rather than a $100 \%$ deficit. Forward modelling shows $\mathrm{NE}-\mathrm{SW}$ convergence in the eastern Explorer plate. 


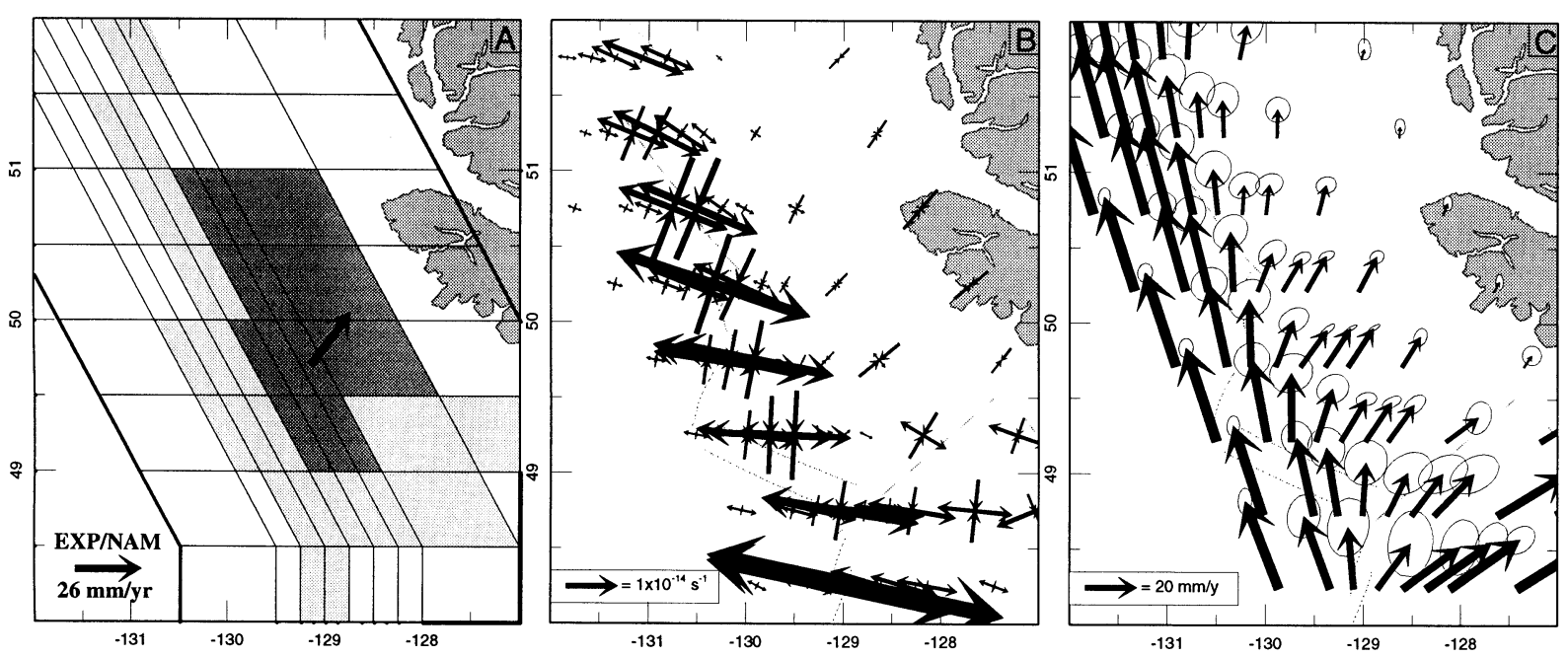

Fig. 9. Same as Fig. 7A, but with an additional relative rigid area, indicated by dark grey grid areas. These areas were given a factor 10 lower variance with respect to white grid areas, causing this area to be more rigid and represent a possible Explorer plate. Black vector is Explorer/NAM relative motion (Davis and Currie, 1993). (B) Principal axes of predicted strain rates. (C) Velocity field relative to NAM.

This is not likely to be all aseismic and since no faults are cutting the sediment cover here (K.M.M. Rohr, pers. commun., 1996) it is doubtful that the micro-plate model is a good representation for the present-day kinematics in the region

\section{Discussion}

The result from the inversion of seismic strain rate distribution for a continuous velocity field reveals that deformation in the Explorer region occurs primarily in a (finite width) transform deformation zone. Since most of the motion related to seismicity is accommodated by this transform zone and the direction of the displacement field is indistinguishable from the NUVEL-1A PAC/NAM relative motion, this 'Explorer transform' zone suggests the (new) PAC-NAM plate boundary, which is supported by the pseudo-plate model (Rohr and Furlong, 1995; Govers et al., 1998). Seismic moment release along this transform plate boundary accommodates $50 \pm 30 \%(1 \sigma)$ of the NUVEL-1A predicted PAC/NAM relative motion, but this number is subject to the choice of shear modulus and seismogenic thickness. It leaves a deficit of $50 \%$ by aseismic deformation, which is a reasonable percentage, although there is no comparison with other strain re- lease studies in regions with similarly young oceanic lithosphere.

The velocity magnitudes and their estimated $1 \sigma$ errors can be considered a reliable estimate of the contribution from the long-term seismic deformation, only if the upper moment cut-off for the Explorer transform zone in the area considered corresponds to an $M_{\mathrm{w}} \sim 7.0$, which is the largest event in our catalogue. We assume this to be true since the region of interest is cut by many faults whose individual lengths are unlikely to exceed $50 \mathrm{~km}$. This combined with the relatively thin seismogenic layer makes a $M_{\mathrm{w}}$ much greater than 7.0 unlikely for this section of the plate boundary zone.

With the Explorer transform zone as the (new) PAC-NAM plate boundary the region on the eastern side of this zone is consequently assumed to be part of the NAM tectonic plate. This implies accretion of the eastern Explorer region to the NAM plate during the last few million years.

Seismicity along the Nootka Transform is consistent with JdF/NAM relative motion, but yields small strain rates. One reason for this lack of seismicity could be that deformation along this plate boundary is almost $100 \%$ aseismic. The other reason could be that it has not ruptured in the almost 50 years of our catalogue. This could be related to the fact that, since we determined the Explorer plate to be part of North 
America, the Nootka Transform is now the northern part of the Cascadia subduction zone, which is currently believed to be locked. Thus Nootka cannot move as long as Cascadia is not moving.

Additional support for the pseudo-plate model comes from recent GPS measurement of crustal deformation in northern Vancouver Island (Dragert and Hyndman, 1995; Henton et al., 1996). A displacement of $2.8 \pm 1.4 \mathrm{~mm} / \mathrm{yr}$ in NE direction at a site on the northern tip of Vancouver Island shows PAC/NAM relative motion at a low rate as we would expect with a transform zone. The result from the forward modelling with the pseudo-plate model predicts a displacement of $3.3 \pm 3.0 \mathrm{~mm} / \mathrm{yr}$ in NNE direction (Fig. 7C). The micro-plate model requires $\sim 20 \mathrm{~mm} / \mathrm{yr}$ of shortening between the Explorer ridge and Vancouver Island (Fig. 9C), which is inconsistent with the GPS measurement.

\section{Conclusions}

Strain rates derived from earthquakes show the presence of an Explorer transform zone, which cuts the Explorer region. The distribution of the strain rates is consistent with surface fault observations (Furlong et al., 1994; Rohr and Furlong, 1997). The velocity field as derived from the inversion of these strain rate data suggest that PAC/NAM relative motion is accommodated along this deformation zone, implying that the region in the east of this zone is part of the NAM plate. Consequently, this deformation zone is the transform plate boundary between the NAM and PAC plates. This is consistent with the pseudo-plate model (Rohr and Furlong, 1995; Govers et al., 1998). Seismic moment release represents $50 \pm 30 \%(1 \sigma)$ of the PAC/NAM relative motion. Earthquake-derived strain rates suggest that significant $\mathrm{JdF} / \mathrm{NAM}$ relative motion (seismic slip) has been absent in the last 48 years. Such motion would have taken place along the Nootka Transform. This absence of seismic slip could be closely linked to the fact that the northern Cascadia subduction zone is locked. Finally, forward modelling shows that the pseudo-plate model is more consistent with the style of earthquake strain rates and the observations of faults cutting the ocean floor than the micro-plate model.

\section{Acknowledgements}

The International Relations Office of Utrecht University is gratefully acknowledged for support of C.K. R.G. and K.P.F. are supported by NATO grant CRG.960139. K.P.F. is also supported by NSF EAR9628347 and W.E.H. by NSF EAR-9118401. Discussions with Saskia Goes were greatly appreciated as well as the critical reviews by Shimon Wdowinski and Kevin Burke. The surface faulting data base for Fig. 4 was prepared by Chris Schneider. We thank the Geological Survey of Canada for providing seismicity data for Fig. 2A. Finally, C.K. and K.P.F. thank the Pacific Geoscience Centre for data access and inclusion in the Explorer cruise in 1996. This work was conducted under the program of the Vening Meinesz Research School of Geodynamics.

\section{References}

Atwater, T., 1989. Plate tectonic history of the northeast Pacific and western North America. In: Winterer, E.L., Hussong, D.M., Decker, R.W. (Eds.), The Geology of North America, N., The Eastern Pacific Ocean and Hawaii. Geol. Soc. Am., Boulder, CO, pp. 21-72.

Botros, M., Johnson, H.P., 1988. Tectonic evolution of the Explorer - Northern Juan de Fuca region from $8 \mathrm{Ma}$ to the present. J. Geophys. Res. 93, 10421-10436.

Bourne, S.J., England, P.C., Parsons, B., 1988. The motion of crustal blocks driven by flow of the lower lithosphere and implications for slip rates of continental strike-slip faults. Nature 391, 655-659.

Braunmiller, J., Nábalek, J., Leitner, B., 1996. Seismotectonics of the Explorer plate region. EOS Trans. AGU 77 (46), 655.

Cassidy, J.F., Rogers, C.G., 1995. The rupture process and aftershock distribution of the 6 April $1992 M_{\mathrm{S}} 6.8$ earthquake, offshore British Columbia. Bull. Seismol. Soc. Am. 85, 716735.

Cassidy, J.F., Ellis, R.M., Hyndham, R.D., 1988. The 1918 and 1957 Vancouver Island earthquakes. Bull. Seismol. Soc. Am. 78, 617-635.

Davis, E.E., Currie, R.G., 1993. Geophysical observations of the northern Juan de Fuca Ridge system: lessons in sea-floor spreading. Can. J. Earth Sci. 30, 278-300.

DeMets, C., Gordon, R.G., Argus, D.D., Stein, S., 1994. Effect of recent revisions to the geomagnetic reversal time scale on estimates of current plate motions. Geophys. Res. Lett. 21, 2191-2194.

Dragert, H., Hyndman, R.D., 1995. Continuous GPS monitoring of elastic strain in the northern Cascadia subduction zone. Geophys. Res. Lett. 22, 755-758.

Dziewonski, A.M., Ekström, G., Salagnik, M.P., 1994. Centroid 
moment tensor solutions for October-December 1993. Phys. Earth Planet. Inter. 85, 215-225.

England, P.C., McKenzie, D.P., 1982. A thin viscous sheet model for continental deformation. Geophys. J. R. Astron. Soc. 70, 295-321.

Furlong, K.P., Rohr, K.M.M., Lowe, C., 1994. Evolution of the Pacific-Juan de-Fuca-North America triple junction. EOS Trans. AGU 75 (44), 620.

Govers, R., Furlong, K.P., Rohr, K.M.M., 1998. The Explorer Region: a case study of the dynamics of a subductionspreading-transform triple junction. J. Geodyn., in revision.

Haines, A.J., 1982. Calculating velocity fields across plate boundaries from observed shear strains. Geophys. J. R. Astron. Soc. 68, 203-209.

Haines, A.J., Holt, W.E., 1993. A procedure for obtaining the complete horizontal motions within zones of distributed deformation from the inversion of strain rate data. J. Geophys. Res. 98, 12057-12082.

Haines, A.J., Jackson, J.A., Holt, W.E., Agnew, D.C., 1998. Representing distributed deformation by continuous velocity fields. Sci. Rept. 98/5, Inst. of Geology and Nuclear Science, Wellington, New Zealand.

Hatheway, A.W., Kiersch, G.A., 1982. Engineering properties of rocks. In: Carmichael, R.S. (Ed.), Handbook of Physical Properties of Rocks, Vol. II. CRC Press, Boca Raton, FL, pp. 307-308.

Henton, J.A., Dragert, H., Hyndman, R.D., Schmidt, M., Flueck, P., 1996. Recent crustal deformation constraints for modelling the locked portion of the Cascadia subduction zone. EOS Trans. AGU 77 (46), 147-148.

Holt, W.E., Haines, A.J., 1995. The kinematics of northern South Island, New Zealand, determined from geological strain rates. J. Geophys. Res. 100, 17991-18010.

Holt, W.E., Li, M., Haines, A.J., 1995. Earthquake strain rates and instantaneous relative motions within central and east Asia. Geophys. J. Int. 122, 569-593.

Hyndham, R.D., Rogers, C.G., 1981. Seismicity surveys with ocean bottom seismographs off western Canada. J. Geophys. Res. 86, 3867-3880.

Jackson, J.A., McKenzie, D.P., 1988. The relationship between plate motions and seismic moment tensors, and the rates of active deformation in the Mediterranean and Middle East. Geophys. J. R. Astron. Soc. 93, 45-73.

Jackson, J.A., Haines, A.J., Holt, W.E., 1995. The accommodation of Arabia-Eurasia plate convergence in Iran. J. Geophys. Res. 100, 15205-15219.

Kostrov, V.V., 1974. Seismic moment and energy of earthquakes, and seismic flow of rocks. Izv. Acad. Sci. USSR Phys. Solid Earth 1, 23-44.

Lonsdale, P., 1991. Structural patterns of the Pacific floor off- shore of peninsular California. In: Dauphin, J.P., Simoneit, B.R.T. (Eds.), The Gulf and Peninsular Province of the Californias. Am. Assoc. Pet. Geol. Mem. 47, 87-124.

McKenzie, D.P., Jackson, J.A., 1983. The relationship between strain rates, crustal thickening, paleomagnetism, finite strain and fault movements within a deforming zone. Earth Planet. Sci. Lett. 65, 182-202.

Nuttli, O.W., 1985. Average seismic source-parameter relations for plate-margin earthquakes. Tectonophysics 118, 161-174.

Riddihough, R., Hyndman, R.D., 1989. Queen Charlotte Islands margin. In: Winterer, E.L., Hussong, D.M., Decker, R.W. (Eds.), The Geology of North America, N., The Eastern Pacific Ocean and Hawaii. Geol. Soc. Am., Boulder, CO, pp. 403411.

Rohr, K.M.M., Furlong, K.P., 1995. Ephemeral plate tectonics at the Queen Charlotte triple junction. Geology 23, 1035-1038.

Rohr, K.M.M., Furlong, K.P., 1997. Images of the initiation of a transform plate boundary. The Explorer Transform zone. In: Abstracts with 29th General Assembly of IASPEI, 10.

Shen-Tu, B., Holt, W.E., Haines, A.J., 1995. Intraplate deformation in the Japanese Islands: a kinematic study of intraplate deformation at a convergent plate margin. J. Geophys. Res. 100, 24275-24293.

Shen-Tu, B., Holt, W.E., Haines, A.J., 1998. The contemporary kinematics of the western United States determined from earthquakes moment tensors. J. Geophys. Res., in press.

Tinnon, M.J., Holt, W.E., Haines, A.J., 1995. Velocity gradients in the northern Indian Ocean inferred from earthquake moment tensors and relative plate velocities. J. Geophys. Res. 100, 24315-24329.

Wahlström, R., Rogers, G.C., Baldwin, R.E., 1990. P-nodal focal mechanisms for large earthquakes offshore Vancouver Island. Geol. Surv. Can., Open-File Rep. 2068, 1-14.

Ward, S.N., 1994. A multidisciplinary approach to seismic hazard in Southern California. Bull. Seismol. Soc. Am. 84, 1293 1309.

Wiens, D.A., Stein, S., 1983. Age dependence of oceanic intraplate seismicity and implications for lithospheric evolution. J. Geophys. Res. 88, 6455-6468.

Wilson, D.S., 1993. Confidence intervals for motion and deformation of the Juan de Fuca plate. J. Geophys. Res. 98, 1605316071.

Zoback, M.L., Zoback, M.D., Adams, J., Assumpcao, M., Bell, S., Bergman, E.A., Blümling, P., Brereton, N.R., Denham, D., Ding, J., Fuchs, K., Gay, N., Gregersen, S., Gupta, H.K., Gvishiani, A., Jacob, K., Klein, R., Knoll, P., Magee, M., Mercier, J.L., Müller, B.C., Paquin, C., Rajendran, K., Stephansson, O., Suarez, G., Suter, M., Udias, A., Xu, Z.H., Zhizhin, M., 1989. Global patterns of tectonic stress. Nature 341, 291-298. 